\title{
Geo-electrical mapping and groundwater potential zoning in some selected pockets of Baromura hill of Tripura (India)
}

\author{
Sudip Dey*, Chandrani Debbarma, Prasamita Sarkar and Sushmita Paul \\ Department of Geography and Disaster Management, Tripura University, Suryamaninagar-799130, INDIA \\ "Corresponding author. E-mail: sudip_geo@rediffmail.com
}

\begin{abstract}
Baromura hill of Tripura is characterised by complex geology and very rugged landform. Water scarcity is a very general problem for the remote hilly villages of this area. Thus groundwater is considered as one of the most valuable natural resources in hilly villages of Baromura hill. The present study aims to prepare small area survey based geo-electrical mapping for understanding groundwater condition in some selected pockets of the study area. For that purpose one hill slope and one trough shaped low land (locally known as lunga) was selected. Soil resistivity meter was used for electrical survey. A circle plot was prepared for geo-electrical survey on the basis of which geo-electrical maps were drawn. In the studied hill slope morphology four sectors of ground water conditions were observed according to their electrical resistivity character namely shallowest zone, medium zone, deep zone and very deep zone. The trough shaped low land (lunga) is characterised by comparatively shallower condition of groundwater and it was divided into five classes namely near surface water, very shallow zone, shallow zone, medium shallow zone and medium zone. Though the depth of the water bearing strata cannot be detected by this method it is very suitable for understanding the groundwater potential zones in remote places like present study area.
\end{abstract}

Keywords: Groundwater, Geo-electrical mapping, Baromura hill, 2-pin survey, Hill slope, Low land

\section{INTRODUCTION}

Groundwater exploration in different physical environmental conditions is one of the most challenging issues in Applied Geophysics and Geotechnical Engineering from methodological stand point due to its application value. From environmental point of view groundwater is considered as an important physical component of the nature since it widely influences soil conditions, vegetation distribution, sustainable irrigation, archaeological sites etc (Gaber et al., 1999; Mesbah, 2003; Mohamaden, 2005). In geophysical researches measuring electrical resistivity of soil is a popular technique for groundwater exploration which has been established by many early workers like Barker (1980), Bernard and Valla, (1991), Nowroozi et al. (1999), Ibrahim et al. (2004) and Nigm et al. (2008) . Many investigations like McNeill (1980) Palacky (1987) Dahlin (1993), Alfano (1993), Dahlin (1996), Christensen and Sørensen (1996), Dahlin and Loke (1997), Yoshida et al. (1997) George et al. (2008) and Akpan et al. (2009) strongly support the efficiency of electrical resistivity technique for understanding the physical characters of various soils/ rocks. Considering the importance of electrical survey in groundwater exploration the present authors decided to experiment on small area geo-electrical mapping for measuring groundwater conditions in some selected pockets of Baromura hill of Tripura. The main objective of this study is to find out an alternative and simple methodology which can be applied in such areas where lack of place, rugged landform and dense cover of vegetation together create problem for multi-electrode geo-electrical survey.

\section{MATERIALS AND METHODS}

$G$ ener al geomor phology and geology of the study area: Geologically Baromura hill is an elongated fold belt with complex structural setting (Dey et al., 2009; Dey et al., 2010) (Fig.1). This area is characterized by undulating / rugged landform which stretches north to south in Tripura. The crest of the anticlines forms the crest of the range and the gentle deep of the flanks form the slopes of the range. The highest elevation of Baromura is observed $197 \mathrm{~m}$ at $23.970416^{\circ} \mathrm{N}$ latitude and $91.520739^{\circ} \mathrm{E}$ longitude. In the south the elevation decreases gradually. The geological successions and their characters of the study area are shown in Table 1.

Selection of survey places: Initially two different microregional level environmental domains were selected for survey which are characterised by very uneven surface and of-course suffering by water scarcity. Geomorphologically the first selected area is a hill slope and the second one is a trough shaped low land within the hills (Plate.1). In both the places $30 \mathrm{~m} \mathrm{X} 30 \mathrm{~m}$ areas 


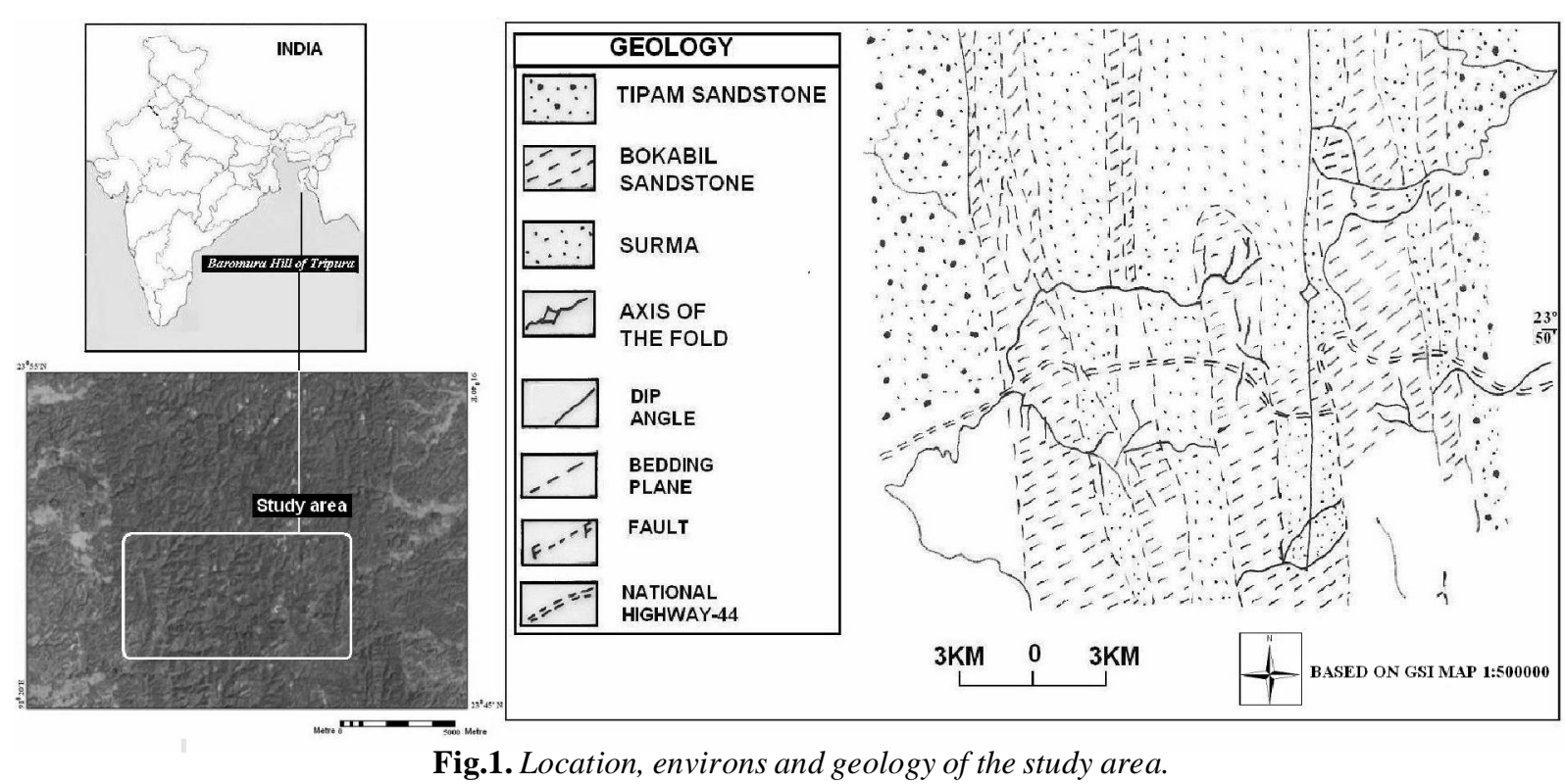

were taken for survey. The basic features of the selected places are as follows:

a) Hill slope: Most of the areas of Baromura Hill are marked by high angle hill slopes which are characterised by dense vegetation cover. Earlier these hill slopes were used for shifting cultivations by the local tribal people. Now rubber plantation has been introduced by the government in many hill slopes. The selected survey place for the present study is a high angle hill slope and located along National Highway 44. The soil of this area is very immature with low organic matter. This hill slope is covered with medium to dense vegetation.

b) Trough shaped low land: These types of lands are commonly found in the hills of Tripura which are locally known as "lungas". These are surrounded by high to medium angle slopes and covered by grasses and bushes. In narrow and elongated low lands rice and vegetable cultivation is done by the villagers. For the present research a deep and trough shaped lunga or lowland was selected from a remote place which is located $1.5 \mathrm{~km}$ north to National Highway 44.

Data gener ation and data analysis: Soil resistivity meter was used for assessing electrical data generation. Since the selected areas are very small and due to uneven

Table 1. Geological successions of Baromura hill. surface condition and vegetation cover application of multi-electrodes is not possible in the present study 2pin method was used for understanding the ground water conditions. For the purpose of the geo-electrical survey two basic conditions was maintained strictly

I. The survey was conducted in a sunny dry day during winter season when the sky was comparatively cloud free and level of moisture in atmosphere was very low.

II. The date of survey was fixed by observing that there was no rain fall for last 30 days, because rainfall influences to change the normal ground water condition. Instead of random selection of points for data generation, which is very common method in 2-pin survey, a circle plot was prepared where reference electrode was fixed in the centre of the circle (Fig.2). Electrode P3 was used as reference point. Electrode P2 was used for electrical measurement on the selected points according to circle plot. For fixing ground control points on the reference electrodes GPS tool was used. The instrument reading was processed in the laboratory (Table. 2 and Fig.3).

\section{RESULTS}

Data classification and groundwater zoning: Recorded data were placed on the circle plots for understanding physical natures of the selected $30 \mathrm{~m} \mathrm{X} \mathrm{30m} \mathrm{survey} \mathrm{places}$

\begin{tabular}{lcccc}
\hline Geological period & Epoch & Group & Formation & Lithology \\
\hline Tertiary & Early Pliocene & Tipam & & $\begin{array}{l}\text { Marine-coastal and } \\
\text { estuarine sand rocks } \\
\text { with shale and fossil } \\
\text { wood. }\end{array}$ \\
\hline $\begin{array}{c}\text { Miocene } \\
\text { Line OF UNCONFORMITY }\end{array}$ & Bokabil & $\begin{array}{c}\text { Marine-coastal Shale } \\
\text { with minor sandstone }\end{array}$ \\
\hline & Surma & & \\
\hline & & & \\
\hline
\end{tabular}

(Source: Extracted from a unpublished report of Geological Survey of India, 2002). 

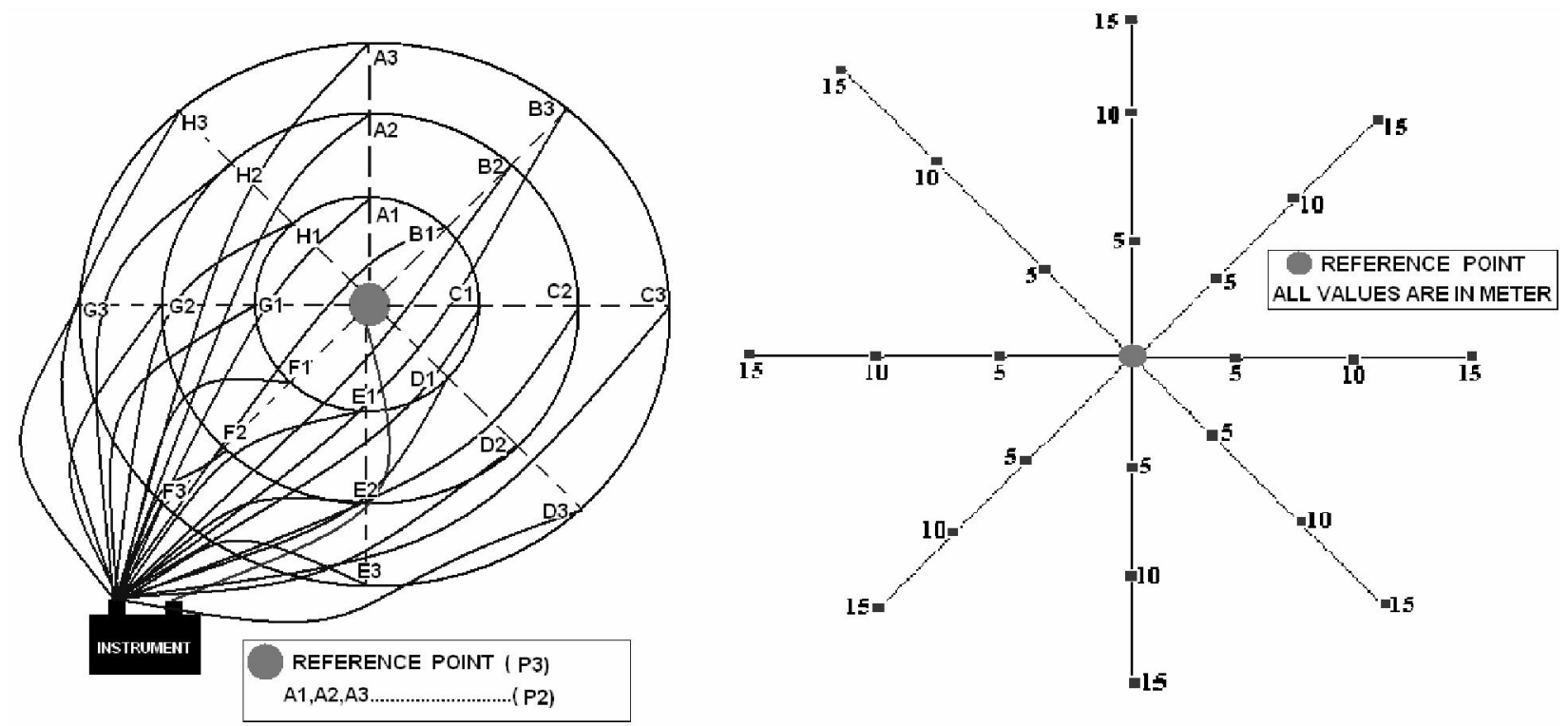

Fig.2. Survey plot for geo-electrical mapping within $30 \mathrm{~m} \times 30 \mathrm{~m}$ areas.

and isopleth mapping was done on the plots. On the basis of the calculated $R$ value 4 classes of groundwater conditions were prepared for hill slope morphology namely shallowest zone or $\mathrm{SZ}(\mathrm{R}=<550 \quad)$, medium zone or $\mathrm{MZ}(\mathrm{R}=550$ to 579$)$, deep zone or $\mathrm{DZ}(\mathrm{R}=.580$ to
610 ) and very deep zone or $\mathrm{VDZ}(\mathrm{R}=>610$ ). From the obtained data it has been sheen that the second survey place is characterised by comparatively shallower condition of groundwater. In case of low land or lunga 5 classes were prepared namely near surface water or NSW

Table 2. Field data processing for classification of groundwater zones.

\begin{tabular}{|c|c|c|c|c|c|}
\hline \multirow{2}{*}{$\begin{array}{l}\text { Stations of } \\
\text { P2 on } \\
\text { circles 1,2 } \\
\text { and } 3\end{array}$} & \multirow{2}{*}{$\begin{array}{l}\text { Distance } \\
\text { from } \\
\text { reference } \\
\text { el ectr ode }\end{array}$} & \multicolumn{2}{|c|}{ Hill slope mor phology } & \multicolumn{2}{|c|}{ Low land or Lunga } \\
\hline & & $\begin{array}{l}\text { Instrument } \\
\text { reading }\end{array}$ & 'R' Obtained (in $\Omega$ ) & $\begin{array}{l}\text { Instrument } \\
\text { reading }\end{array}$ & 'R' Obtained (in $\Omega$ ) \\
\hline $\mathrm{A} 1$ & 5 Metre & 0.648 & 648 & 0.220 & 220 \\
\hline B1 & & 0.609 & 609 & 0.384 & 384 \\
\hline $\mathrm{C} 1$ & & 0.645 & 645 & 0.402 & 402 \\
\hline D1 & & 0.590 & 590 & 0.403 & 403 \\
\hline E1 & & 0.574 & 574 & 0.358 & 358 \\
\hline $\mathrm{F} 1$ & & 0.537 & 537 & 0.379 & 379 \\
\hline G1 & & 0.600 & 600 & 0.375 & 375 \\
\hline $\mathrm{H} 1$ & & 0.652 & 652 & 0.374 & 374 \\
\hline $\mathrm{A} 2$ & 10 Metre & 0.589 & 589 & 0.239 & 239 \\
\hline B2 & & 0.493 & 493 & 0.360 & 360 \\
\hline $\mathrm{C} 2$ & & 0.646 & 646 & 0.300 & 300 \\
\hline D2 & & 0.552 & 552 & 0.374 & 374 \\
\hline E2 & & 0.534 & 534 & 0.377 & 377 \\
\hline F2 & & 0.544 & 544 & 0.386 & 386 \\
\hline $\mathrm{G} 2$ & & 0.634 & 634 & 0.394 & 394 \\
\hline $\mathrm{H} 2$ & & 0.606 & 606 & 0.372 & 372 \\
\hline A3 & 15 Metre & 0.584 & 584 & 0.250 & 250 \\
\hline B3 & & 0.534 & 534 & 0.344 & 344 \\
\hline $\mathrm{C} 3$ & & 0.580 & 580 & 0.374 & 374 \\
\hline D3 & & 0.531 & 531 & 0.381 & 381 \\
\hline E3 & & 0.554 & 554 & 0.397 & 397 \\
\hline F3 & & 0.539 & 539 & 0.396 & 396 \\
\hline G3 & & 0.669 & 669 & 0.398 & 398 \\
\hline $\mathrm{H} 3$ & & 0.624 & 624 & 0.387 & 387 \\
\hline
\end{tabular}

$\mathrm{R}=$ Instrument reading X Range of the instrument Range of the instrument X10 $0^{3}$ Voltage-50V 


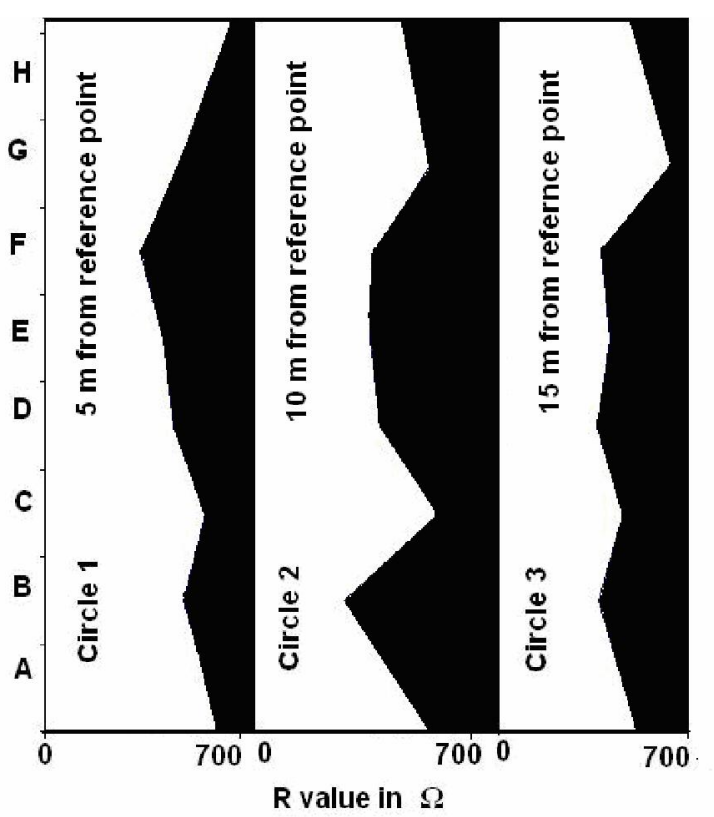

a

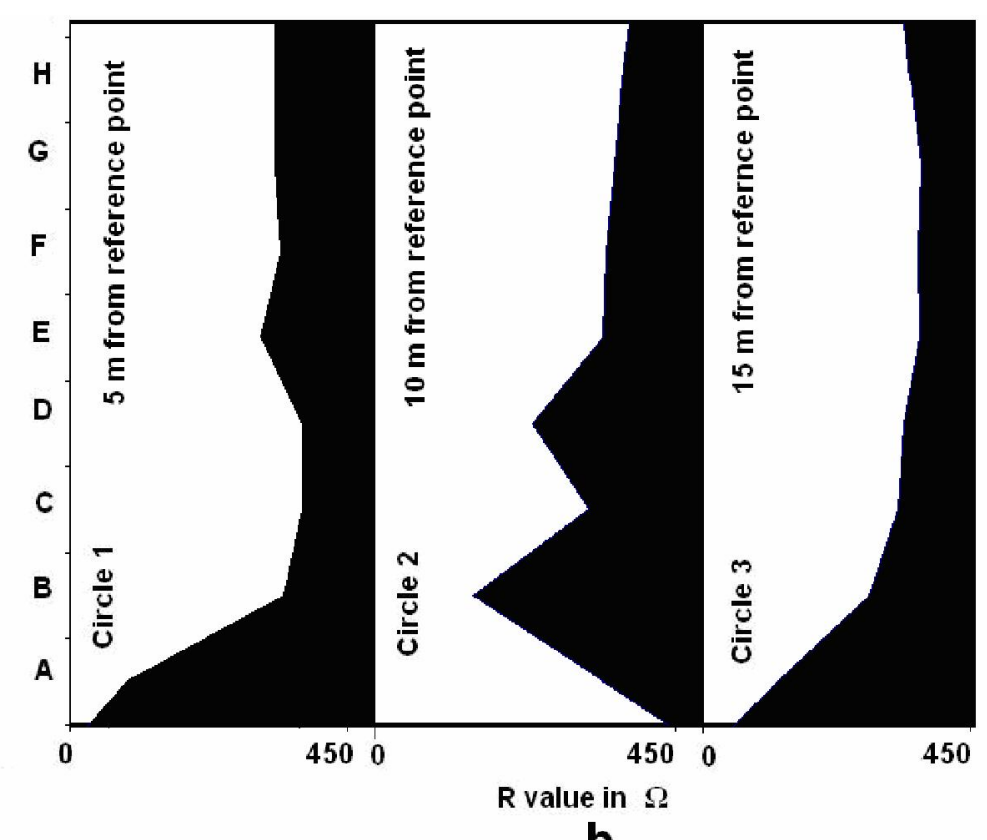

b

Fig. 3. Geo-electrical data on A to $\mathrm{H}$ points of every circle (a) hill slope morphology and (b) low land.

$(\mathrm{R}=<330$ ), very shallow zone or $\mathrm{VSZ}(\mathrm{R}=0.330$ to 349 ), shallow zone or $\mathrm{SZ}(\mathrm{R}=350$ to 369 ), medium shallow zone or MSZ $(\mathrm{R}=370 \quad$ to $390 \mathrm{U})$ and medium zone or $\mathrm{MZ}(\mathrm{R}=>390$ ).

Geo-electrical natur e of hill slopemor phology: Maximum deep water level (VDZ) was found at the eastern, southeastern and middle parts of this survey place where $R$ value measured $>610$. Slope angle of this part is very high and covered by grass to medium vegetation cover. Near the VDZ, in some pockets, $\mathrm{R}$ value varies between 550 to 610 which indicates the comparatively decrease of depth of water bearing strata from the surface. At many parts of southern, south-west, north-west to north eastern side of the survey place this range has been found which fall $\mathrm{MZ}$ and $\mathrm{VZ}$ classes. An evidence of medium deep condition of the water bearing strata (MZ) has been found at south, south-west, and pockets of north-west, north and north east sides where $\mathrm{R}$ value recorded between 550 to 579 . The shallowest ground water zone (SZ) has been detected in two parts namely south-west and northern-eastern and $\mathrm{R}$ value measured bellow $550 \quad$ (Fig.4a). In the northern part the minimum $\mathrm{R}$ value recorded 493 which can be considered as the best place for ground water exploration. This is comparatively lower slope and elevation is also comparatively low.

Trough shaped low land (lunga): From the instrument data it has been seen that the water bearing strata is comparatively close to the surface than the hill slope (Fig.4b). Higher R value recorded (>390 ) at northern and eastern parts (MZ) which indicates the deepest ground water condition in those places. At some points of north-west and middle parts $\mathrm{R}$ value measured between
370 to 390 (MSZ). Some portions of west, south-east and middle of this place are characterised by $\mathrm{R}$ value range between 350 to 369 (SZ). It has been observed that with the decrease of $R$ value the amount of grass on the surface is increased and they become greener in colour. It indicates the shallow condition of water bearing strata.

Towards south there is a small wet land and ground water condition become very shallow (NSW). The R value varies from 330 to 350 at middle and southern parts.

The lowest ground water condition is detected 220 at the middle part of this area which can be considered as the best place for tube well from financial point of view. From this place easily ground water can be extracted by minimum drilling.

\section{DISCUSSION}

In many recent experimental works vertical electrical sounding, multi-electrode methods and electromagnetic very low frequency profiling have been successfully applied for wide area groundwater exploration which reflects in the researches of Owen et al. (2005), Hamzah et al. (2007) and Ariyo et al. (2009). Geomorphologically the present study area Baromura hill of Tripura is characterised by very rugged landform and that causes groundwater exploration very difficult as a suitable flat land is rarely available in this place for geo-electrical survey. Geological complexity is another problem for groundwater exploration in this fold area though water scarcity is a very general problem to the local people and groundwater is considered as a valuable natural resource. Hence 2-pin method is the most suitable for understanding the physical nature of the soil and 

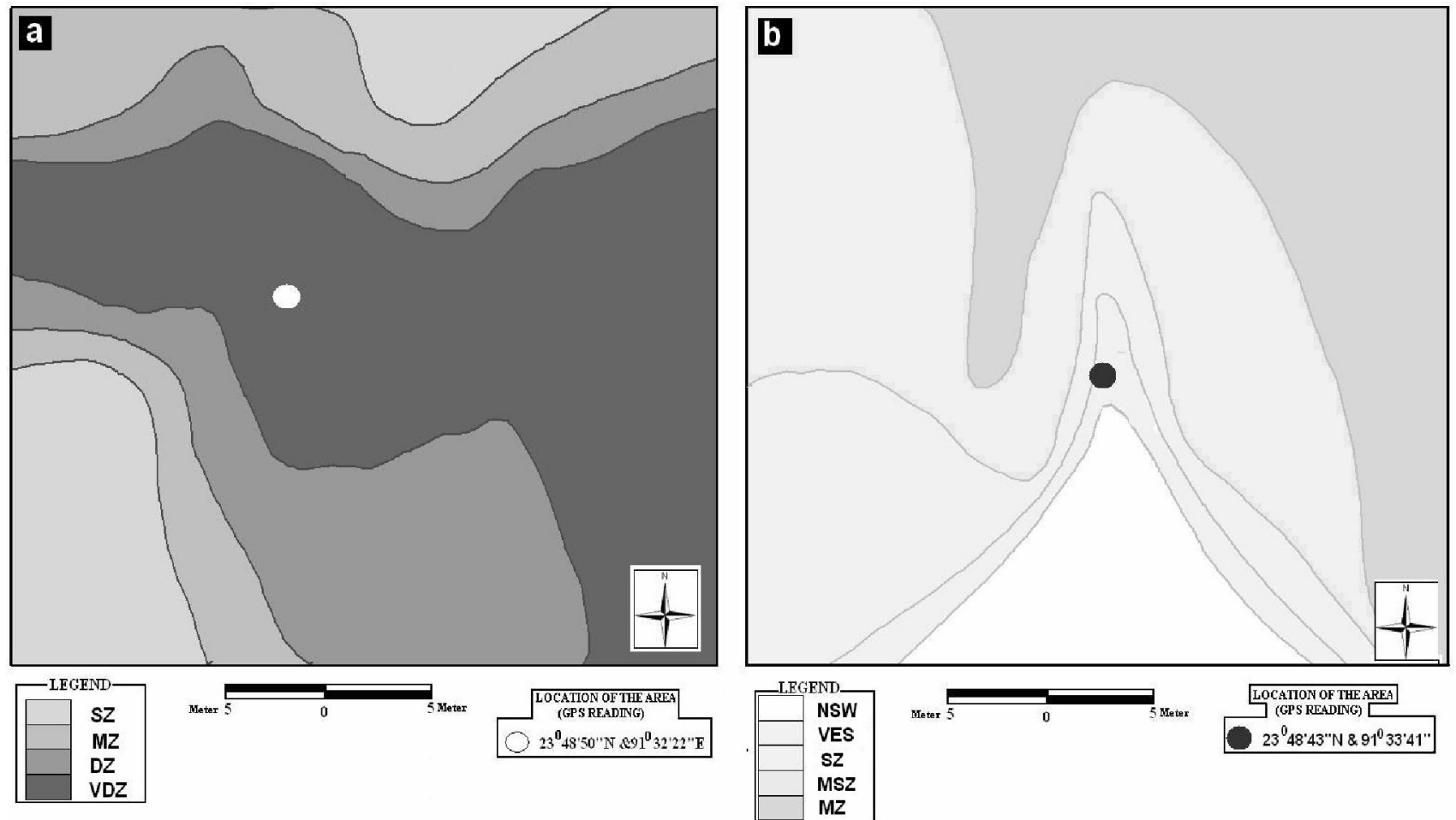

Fig.4. G eo-electrical mapping for assessing ground water condition in (a) hill slope and (b) low land (lunga).
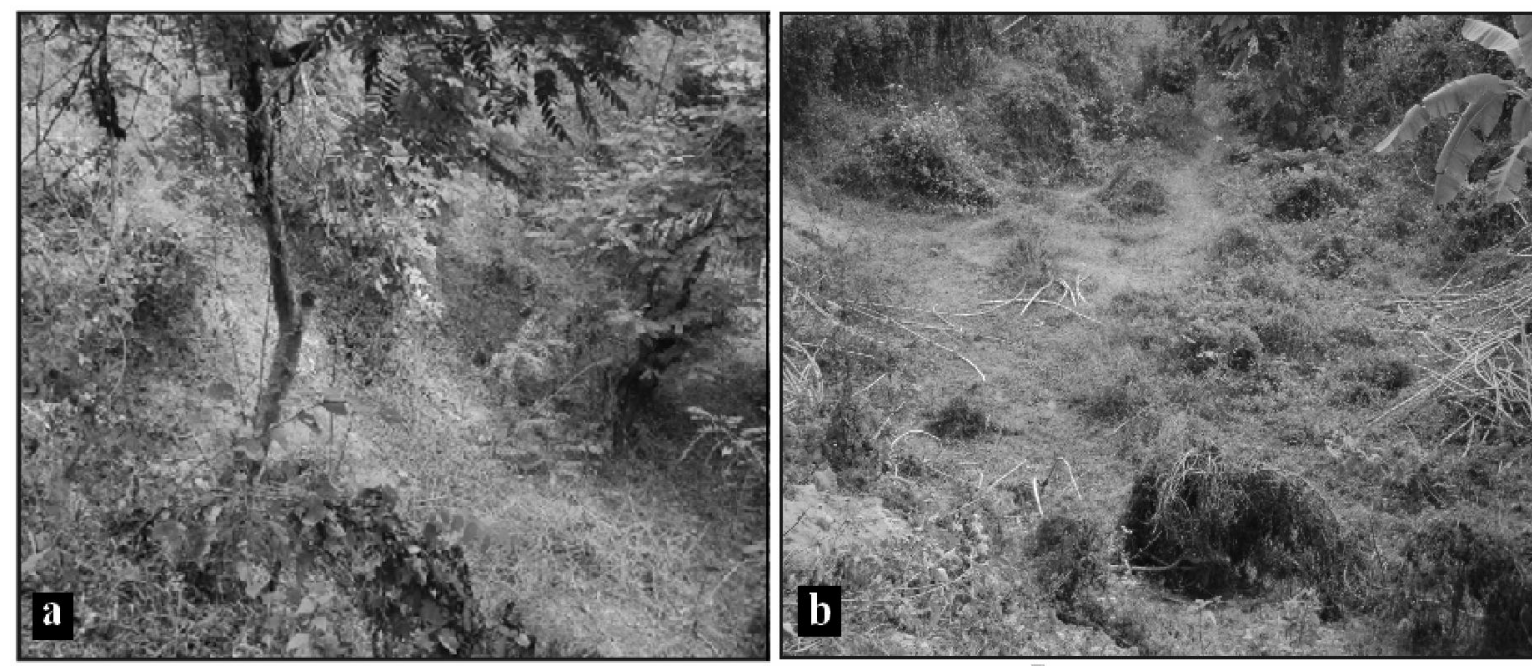

Plate.1. M orphology of (a) hill slope and (b) low land (lunga).

groundwater condition. During the study both merits and demerits of the applied method was observed. It is a simple method and not time-consuming at all. Circle plot can be prepared even in a very uneven land where many types of obstructions create problem for maximum number of data generation if random selection of survey points are done. Besides that the demerits of this method are also opened during the research. The main demerit of this method is that this method only can give an idea about the groundwater distribution without measuring the depth of water bearing strata. However this method can be very helpful for assessing the groundwater condition in the remote areas for construction of wells or for locating a perfect place for tube well.

\section{REFERENCES}

Akpan A.E., George N. J., and George A.M.(2009). Geophysical investigation of some prominent gully erosion sites in Calabar, southeastern Nigeria and its implications to hazard prevention, J. Disaster Advances, 2 (3) : 46-50.

Alfano L.,(1993). Geoelectrical methods applied to structures of arbitrary shapes, J ournal of Applied G eophysics, 29 (3/ 4): 193-209.

Ariyo, S.O., Adeyemi, G.O. and Oyebamiji, A.O. (2009). Electromagnetic Vlf Survey for Groundwater Development in a Contact Terrain; a Case Study of Ishara-remo, Southwestern Nigeria. J ournal of Applied Sciences Research, 5 (9): 1239-1246.

Barker, R.D. (1980) Application of geophysics in groundwater investigations. Water Surv., 84:489-492. 
Bernard, J. and Valla, P. (1991) Groundwater exploration in fissured media with electric and VLF methods. G eoexploration, 27: 81-91.

Christensen, N.B. and Sorensen, K.(1996). Pulled array continuous electrical sounding PA-CVES, with an additional inductive source. In: Proc SAGEEP'96 (Symposium on the Application of Geophysics to Engineering and Environmental Problems). Environmental and Engineering Geophysical Society, Wheat Ridge, USA, 1-10

Dahlin, T.(1993). On the automation of 2D resistivity surveying for engineering and environmental applications. (PhD Thesis) Lund University, Sweden.

Dahlin, T. (1996). 2D resistivity surveying for environmental and engineering applications. First Break, 14: 275-283

Dahlin, T. and Loke, M.H.(1997). Quasi-3D resistivity imaging -mapping of three dimensional structures using two dimensional DC resistivity techniques. In: Proc 3rd M eeting Environmental and Engineering G eophysics. Environmental and Engineering Geophysical Society, European Section, Aarhus, Denmark, 143-146

Dey, S.,Debbarma,C., Sarkar, P. and Marfai, M.A. (2010) Experiment on visualising micro-level surface characters of sediment sections: a methodological approach to reflectance based alternative petrographic image analysis: Arabian J ournal of G eoscience, Springer, DOI: 10.1007/s12517-0100122-5

Dey, S., Sarkar, P. and Debbarma,C. (2009). Morphological signatures of fault lines in an earthquake prone zone of southern Baromura hill, north-east India: a multi sources approach for spatial data analysis. Environmental Earth Sciences; Springer; DOI 10.1007/s12665-009-0033-5 Vol59: 353-361

Gaber, S., El-Fiky, A.A., Abou Shagar, S. and Mohamaden, M. (1999). Electrical Resistivity Exploration of the Royal Ptolemic Necropolis in the Royal Quarter of Ancient Alexandria, Egypt. Archaeological Prospection, 6: 1-10.

George, N.J., Akpabio, G.T. and Evans, U.F. (2008).Study of failed tarred roads using earths resistivity values from local communities in Ukanafun local government area ,Akwa Ibom state,Nigeria. Integrated J ournal of Physical Sciences,3(1),1-5.

Hamzah, U., Samsudin, A. R. and Malim, E. P. (2007) Groundwater investigation in Kuala Selangor using vertical electrical sounding(VES) surveys, Environ. G eol., 51:1349-1359.

Ibrahim, E.H., Shereef, M.R., El Galladi, A.A. and Pederson, L.B. (2004). Geoelectric Study on Quaternary Groundwater Aquifers in Northwest Sainai, Egypt, Geophysical Society J ournal, 2(1): 69-74.

Mc Neil, J.D. (1980). Electrical Conductivity of soils and rocks. Technical Note TN -5.Geonics Limited, Mississauga, Ontario, Canada.

Mesbah, M.A. (2003). Groundwater Environmental Prospection using electrical Resistivity Survey at the New Kattamiya City, Near Cairo, Egypt, Annals of Geological Survey of Egypt, XXVI: 409-420.

Mohamaden, M.I.I. (2005). Electric Resistivity Investigation at Nuweiba Harbour of Aqaba, South Sinai, Egypt, Egyptian. J ournal of A quatic Research, 31(1): 58-68.

Nigm, A.A., Elterb, R. A., Nasr, F.E. and Thobaity, H.M. (2008). Contribution of Ground Magnetic and Resistivity Methods in Groundwater Assessment in Wadi Bany Omair. Holy Makkah Area, Saudi Arabia, Egyptian. Geophysical Society J ournal, 6(1): 67-79.

Nowroozi, A., Horrocks, B. and Henderson, P. (1999). Saltwater intrusion into the freshwater aquifer in the eastern shore of Virginia: a reconnaissance electrical resistivity survey. J . Applied G eophysics, 42: 1-22.

Owen R. J., Gwavava, O., and Gwaze P. (2005). Multielectrode resistivity survey for groundwater exploration in the Harare greenstone belt, Zimbabwe. Hydrogeology J ournal, 14: 244-252.

Palacky, G. J. (1987). Resistivity characteristics of geologic targets. In: Nabighian M N (ed) E lectromagnetic methods in applied geophysics. Soc. Explor Geophys, Tulsa.

Yoshida, H., Tanaka, N. and Hozumi, H. (1997). Theoretical study on heat transport phenomena in a sanitary landfill. In: Proceedings Sardinia, 97. 